\title{
Diversification in Portfolio Risk Management: The Case of the UAE Financial Market
}

\author{
Ikhlaas Gurrib and Saad Alshahrani
}

\begin{abstract}
The paper looks at the existence of portfolio risk management for the UAE Financial Market. The research methodology centers on applying Modern Portfolio Theory, with particular emphasis on the Markowitz Efficient Frontier, Minimum Variance Analysis, and Portfolio Optimization. The data is essentially based on the top performing sectors of the UAE economy, and twenty key companies are chosen from each sector to test for diversification. Key findings suggest that the risk of the portfolio is lower than the weighted risk of the twenty individual stocks, i.e. efficient diversification can be achieved.
\end{abstract}

Index Terms-Efficient diversification, portfolio optimization, UAE financial market.

\section{INTRODUCTION}

The objective of investors and, particularly, portfolio managers is to attain the optimal trade off amid risk of a portfolio of investment and the return expected from it. In the portfolios built from a set number of assets or financial securities, the risk and return characteristics would change with the composition of the portfolio. The portfolio that is expected to generate the maximum return at a particular level of risk, or alternatively stated, the portfolio of securities that would minimize the rise for a particular level of return, is termed as an optimal portfolio. A collection of such optimal portfolios form a curve in the risk-return graph and is known as the efficient frontier [1].

It is generally accepted in finance literature that the systematic risk involved in any stock cannot be mitigated and hence a portfolio cannot be diversified completely. However, the Markowitz model proposes that it is feasible to lessen the extent of risk under diversifiable risk. Any individual who wants to make investments in financial securities has to choose securities from a huge array of financial assets. The choice of securities to be included in a portfolio should rely on the risk and return attributes of the individual securities. It should be noted that the risk and return attribute of a portfolio of securities is different from the risk return attribute of the assets used in forming the portfolio. Moreover, the correlation of one security with the other is also a very important factor, while considering which securities should be included in a portfolio. If all the securities included in a portfolio are positively correlated to each other's price movements and hence move in the same direction, then, when the market faces financial depression, all the securities

Manuscript received October 19, 2012; revised November 20, 2012.

I. Gurrib is with the Canadian University of Dubai, Sheikh Zayed Road, PO Box 117781, Dubai, United Arab Emirates (e-mail: ikhlaas@cud.ac.ae).

S. Alshahrani is with the International Monetary Fund (IMF), Fiscal Affairs Department, 700 19th St, Washington, DC 20431, USA. (e-mail:salshahrani@imf.org). would simultaneously underperform. Consequently, the risk involved in such a portfolio would remain high. The goal of portfolio formation is to diversify and minimize the risk involved. Thus, the securities that have minimum correlation with each other should be included in a portfolio, so as to generate the maximum portfolio return while minimizing the risk [2].

This study would conduct a portfolio management analysis of a portfolio formed by 20 publicly listed companies in the United Arab Emirates. The analysis would attempt to demonstrate if efficient diversification can be accomplished by exercising the Markowitz model. We would attempt to find out the most favorable investment allocations in a portfolio. To encompass the characteristic of the whole UAE market as a whole, the twenty stocks chosen for this assignment were selected from five different industries, ranging from banking, telecommunication, insurance, real estate and transportation. The main objective of this study is to find out if it is possible to build an efficient frontier using UAE based securities. The Dubai Financial Market (DFM) is one of the most prominent stock exchanges in UAE and had around sixty companies listed to it.

\section{DATA}

For the portfolio formation and creation of the efficient frontier, twenty companies, whose stocks trade in the Dubai Financial Market, were chosen. With the intension of forming an optimal diversified portfolio, the stocks were selected from five diverse industries, to be precise, Banking, Real Estate \& Construction, Transportation, Telecommunication and Insurance [3]. The names of the twenty companies selected for the portfolio formation have been clustered below with regards to their respective industries:
A. Real Estate \& Construction
1) Arabtec Holding PJSC (ARTC)
2) Emaar Properties PJSC (EMAAR)
3) Union Properties PJSC (UPP)
4) Deyaar Development PJSC (DEYAAR)
5) Drake \& Scull International P.J.S.C (DSI)

\section{B. Transportation}

1) Air Arabia PJSC (AIRARABIA)

2) Gulf Navigation Holding PJSC (GULFNAV)

3) ARAMEX PJSC (ARMX)

C. Bank

1) AJMAN BANK PJSC (AJMANBANK)

2) AL SALAM BANK SUDAN (ALSALAMSUDAN)

3) TAMWEEL PJSC (TAMWEEL)

4) Dubai Islamic Bank (DIB) 
5) Al Salam Bank -Bahrain (SALAM_BAH)

6) Gulf Finance House B.S.C (GFH)

\section{Insurance}

1) Dubai Islamic Insurance and Reinsurance Co. (AMAN)

2) Islamic Arab Insurance Company (SALAMA)

3) Takaful House (DARTAKAFUL)

4) Takaful Emarat (PSC) (TAKAFUL-EM)

\section{E. Telecommunication}

1) Hits Telecom Holding K.S.C. (HITSTELEC)

2) Emirate Integrated Telecommunications Company PJSC (DU)

Subsequent to choosing the 20 companies for the portfolio formation and diversification, the daily closing prices of the companies' stocks for the period starting from September
2011 to August 2012 were gathered. The mean value of the stock prices, their variances and the rate of return produced by the twenty stocks when held for one year (explicitly, Sept 2011 to Aug 2012) were calculated, using the collected share price movements from the official website of the Dubai Financial Market. Table I shows the mean stock prices, share price variance and returns if stocks were hold for one year. It can be observed from the above table, that the shares of Arabtec Holding produced the highest return (approximately $103 \%$ ), if they were bought and held for a period of one year. Additionally, it can be observed that the variance of its share price, usually used as a proxy of risk, was one of the highest among the chosen companies.

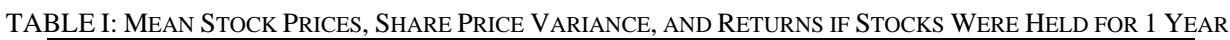

\begin{tabular}{|c|c|c|c|c|}
\hline & Companies & $\begin{array}{l}\text { Mean Stock } \\
\text { Price }\end{array}$ & $\begin{array}{l}\text { Share Price } \\
\text { Variance }\end{array}$ & $\begin{array}{l}\text { Returns if stocks } \\
\text { would have been } \\
\text { held for one year }\end{array}$ \\
\hline 1 & (GULFNAV) Gulf Navigation Holding & 0.26 & $0.2560 \%$ & $-13.79 \%$ \\
\hline 2 & (DEYAAR) Deyaar Development & 0.3 & $0.4820 \%$ & $28.57 \%$ \\
\hline 3 & (UPP) Union Properties & 0.36 & $0.4280 \%$ & $2.63 \%$ \\
\hline 4 & $\begin{array}{c}\text { (SALAM_BAH) Al Salam Bank - } \\
\text { Bahrain }\end{array}$ & 0.43 & $0.2240 \%$ & $-12.50 \%$ \\
\hline 5 & (GFH) Gulf Finance House & 0.59 & $1.7130 \%$ & $8.51 \%$ \\
\hline 6 & (TAKAFUL-EM) Takaful Emarat & 0.61 & $0.3470 \%$ & $-1.59 \%$ \\
\hline 7 & (DARTAKAFUL) Takaful House & 0.62 & $0.4300 \%$ & $-1.67 \%$ \\
\hline 8 & (AIRARABIA) Air Arabia & 0.63 & $0.2260 \%$ & $6.45 \%$ \\
\hline 9 & $\begin{array}{l}\text { (SALAMA) Islamic Arab Insurance } \\
\text { Company }\end{array}$ & 0.66 & $0.9690 \%$ & $-1.43 \%$ \\
\hline 10 & $\begin{array}{l}\text { (AMAN) Dubai Islamic Insurance and } \\
\text { Reinsurance Co. }\end{array}$ & 0.74 & $5.3540 \%$ & $51.67 \%$ \\
\hline 11 & (AJMANBANK) AJMAN BANK & 0.81 & $0.0650 \%$ & $-1.23 \%$ \\
\hline 12 & (DSI) Drake \& Scull International & 0.86 & $0.6900 \%$ & $1.16 \%$ \\
\hline 13 & (TAMWEEL) TAMWEEL & 0.96 & $7.2670 \%$ & $51.25 \%$ \\
\hline 14 & (HITSTELEC) Hits Telecom Holding & 0.97 & $8.1750 \%$ & $53.33 \%$ \\
\hline 15 & $\begin{array}{l}\text { (ALSALAMSUDAN) AL SALAM } \\
\text { BANK SUDAN }\end{array}$ & 1.62 & $3.0280 \%$ & $-5.59 \%$ \\
\hline 16 & (ARMX) ARAMEX & 1.8 & $0.2150 \%$ & $-1.67 \%$ \\
\hline 17 & (DIB) Dubai Islamic Bank & 1.98 & $1.0344 \%$ & $-3.47 \%$ \\
\hline 18 & (ARTC) Arabtec Holding & 2.36 & $61.0480 \%$ & $102.92 \%$ \\
\hline 19 & (EMAAR) Emaar Properties & 2.89 & $7.7720 \%$ & $16.14 \%$ \\
\hline 20 & $\begin{array}{l}\text { (DU) Emirate Integrated } \\
\text { Telecommunications Company }\end{array}$ & 3.04 & $2.5850 \%$ & $12.17 \%$ \\
\hline
\end{tabular}

\section{METHODOLOGY}

\section{A. Portfolio Management}

The technique of reducing the risk by investing in different types of assets is referred as diversification. In other words, diversification is a process of risk management that takes into account a broad selection of investments within a portfolio. Portfolio diversification is crucial in the process of portfolio risk management because it enables the investors to considerably reduce their portfolio risk without compromising their portfolio return. A portfolio that is diversified will have less risk in comparison to the weighted average risk of the constituent assets when the values of the assets do not fluctuate in a perfect synchrony. The rationale that guides this technique argues that a portfolio consisting of different kinds of investment, on average, will give higher returns as well as posture a lower risk compared to any other individual investment that is found within the portfolio. The purpose of diversification is to nullify the unsystematic risk events within a portfolio. Consequently, the positive performance of some investments will rule out the not so positive or negative performance of the other investments. The benefits from the process of diversification can only be accrued if the securities within the portfolio are perfectly uncorrelated [4].

There are generally, two styles of diversification, one vertical diversification and the other horizontal diversification. In case of horizontal diversification, an investor invests his capital in different types of a particular asset group. This mode of diversification is commonly observed in case of shares, where investors invest in shares of 
companies across industries and regions so as to reduce the sector-specific perils. On the other hand, in vertical diversification, an investor invests his money among different categories of assets such as stocks, bonds, cash, property and derivatives among others. These asset categories are anticipated to behave unlike each other and produce dissimilar returns with respect to the changes in the economic scenario. Thus, the negative or not so good performances of certain assets are compensated by the superior performance of other asset groups.

In the year 1952, Harry Markowitz, deemed as the father of Modern Portfolio Theory, developed a framework for the systematic selection of assets in a portfolio on the basis of the principles of risk and return. He was the foremost individual to point out that the interrelationship between the returns of the constituent assets should be taken into consideration in the computation of portfolio risk. This is because the consideration of the interrelationships assists in the reduction of the portfolio risk to the least possible level for a specified level of portfolio return [5]. The concept of portfolio diversification is based on the fact that the cumulative risk of a portfolio is less than the summation of the risks of the individual assets included in the portfolio. The risk of a portfolio is an exclusive attribute and not just the summation of individual asset risks [6]. For instance, a particular security has high risk if held individually but a reduced amount of risk when comprised in a portfolio [7]. Markowitz model of portfolio diversification is based on two approaches, first, minimizing the risk for a given level of expected return, or second, maximizing the expected return for any given level of risk. The risk or variance of a portfolio of stocks is equivalent to the weighted average covariance of the individual stock returns. The variance of a portfolio can be represented by the following equation:

$$
\operatorname{Var}\left(r_{p}\right)=\sigma_{p}^{2}=\sum_{i=1}^{n} \sum_{j=1}^{n} w_{i} w_{j} \operatorname{Cov}\left(r_{i}, r_{j}\right)
$$

where $w_{\mathrm{i}}$ and $w_{\mathrm{j}}$ are the respective weights of two pair of stocks in the portfolio and $r_{\mathrm{i}}$ and $r_{\mathrm{j}}$, their respective returns. The covariance between the returns of two pair of stocks is equal to the product of the correlation coefficient between the stock returns and the corresponding standard deviations. The equation for covariance is as follows:

$$
\operatorname{Cov}\left(r_{i}, r_{j}\right)=\rho_{i j} \sigma_{i} \sigma_{j}=\sigma_{i j}
$$

where $\rho_{i j}$ is the correlation coefficient. It should be noted that an elevated covariance between the returns of two stocks indicates that a raise in the return of one stock would result in a simultaneous raise in the return of the other [8]. On the other hand, zero or low covariance signifies that the returns of the involved stocks are comparatively independent of each other, while a negative covariance implies that a raise in one stock's return would match a corresponding decline in another stock's return. For an efficient diversification of risk in a portfolio, it is necessary that securities whose returns have negative or very low covariance to each other be included in the portfolio, as supported in [9].

\section{B. Minimum Variance Portfolio}

The computation of the minimum variance portfolio and the efficient frontier require the study of the historical share price movements of the 20 considered companies, in order to calculate their standard deviations and their returns. The monthly returns of the 20 companies over a period of one year were used to compute the correlation and the covariance matrixes for the selected stocks. This is accomplished with the help of the Data Analysis tool of Microsoft Excel $@$. The snapshots of the two matrixes are shown in Table II. The covariance matrix so obtained was then converted to a weighted covariance matrix in order to include the weights of the respective stocks in the portfolio. The variance of the portfolio was the summation of the weighted values of the covariance matrix. Since, the assignment involved 20 stocks; the manual computation of the minimum variance portfolio was not possible. The computation of the minimum variance portfolio required the use of Solver Function; where in the standard deviation of the portfolio was set as target to be minimized, by changing the respective weights of the 20 stocks. However, there were two constraints that were used, first, the sum of the weights of all the securities would add up to $100 \%$ or 1 , and second, the individual weights of each of the stocks would be greater or equal to zero as supported in [9].

\begin{tabular}{|c|c|c|c|c|c|c|c|c|c|c|c|c|}
\hline & \multirow[b]{2}{*}{ AJMAN BANK } & \multirow{2}{*}{$\begin{array}{l}\text { AL SALAM BANK } \\
\text { SUDAN }\end{array}$} & \multirow{2}{*}{$\begin{array}{c}\text { Dubai Islamic } \\
\text { Bank }\end{array}$} & \multirow{2}{*}{ Al Salam Bank- } & \multirow{2}{*}{$\begin{array}{l}\text { Arabtec } \\
\text { Holding }\end{array}$} & \multirow{2}{*}{$\begin{array}{c}\text { Deyaar } \\
\text { Development }\end{array}$} & \multirow[b]{2}{*}{ DSI } & \multirow[b]{2}{*}{ EMMAR } & \multirow[b]{2}{*}{ AIRARABIA } & \multicolumn{3}{|c|}{ GULFNA } \\
\hline & & & & & & & & & & ARMX & v & DU \\
\hline AJMAN BANK & 1.00 & & & 3 & & & & & & & & \\
\hline AL SALAM BANK SU & 0.78 & 1.00 & & & & & & & & & & \\
\hline Dubai Islamic Bar & -0.03 & 0.15 & 1.00 & & & & & & & & & \\
\hline Al Salam Bank -Ba & 0.74 & 0.68 & 0.16 & 1.00 & & & & & & & & \\
\hline Arabtec Holding & 0.74 & 0.81 & 0.49 & 0.82 & 1.00 & & & & & & & \\
\hline Deyaar Developm! & 0.65 & 0.68 & 0.22 & 0.89 & 0.82 & 1.00 & & & & & & \\
\hline DSI & 0.26 & 0.45 & 0.73 & 0.45 & 0.60 & 0.58 & 1.00 & & & & & \\
\hline EMMAR & 0.30 & 0.27 & 0.66 & 0.37 & 0.55 & 0.44 & 0.83 & 1.00 & & & & \\
\hline AIRARABIA & 0.08 & 0.26 & 0.74 & 0.48 & 0.52 & 0.61 & 0.77 & 0.53 & 1.00 & & & \\
\hline ARMX & 0.78 & 0.70 & 0.19 & 0.68 & 0.77 & 0.59 & 0.23 & 0.40 & 0.25 & 1.00 & & \\
\hline GULFNAV & 0.69 & 0.73 & 0.24 & 0.93 & 0.87 & 0.99 & 0.55 & 0.41 & 0.59 & 0.65 & 1.00 & \\
\hline DU & 0.32 & 0.47 & 0.40 & 0.40 & 0.49 & 0.60 & 0.89 & 0.73 & 0.56 & 0.15 & 0.55 & 1.00 \\
\hline HitsTele & -0.30 & -0.01 & 0.81 & -0.12 & 0.25 & -0.10 & 0.49 & 0.36 & 0.39 & -0.19 & -0.07 & 0.20 \\
\hline UPP & 0.74 & 0.68 & 0.26 & 0.94 & 0.90 & 0.94 & 0.53 & 0.45 & 0.54 & 0.66 & 0.97 & 0.52 \\
\hline TAMWEEL & 0.49 & 0.39 & 0.29 & 0.74 & 0.67 & 0.87 & 0.65 & 0.56 & 0.55 & 0.27 & 0.83 & 0.69 \\
\hline GFH & 0.57 & 0.75 & 0.55 & 0.79 & 0.91 & 0.83 & 0.70 & 0.52 & 0.64 & 0.57 & 0.85 & 0.52 \\
\hline AMAN & 0.77 & 0.66 & 0.10 & 0.91 & 0.85 & 0.90 & 0.30 & 0.30 & 0.41 & 0.77 & 0.93 & 0.32 \\
\hline DARTAKAFUL & 0.84 & 0.83 & 0.01 & 0.88 & 0.79 & 0.87 & 0.40 & 0.29 & 0.35 & 0.73 & 0.88 & 0.42 \\
\hline SALAMA & 0.74 & 0.73 & 0.27 & 0.94 & 0.89 & 0.98 & 0.57 & 0.48 & 0.61 & 0.73 & 0.99 & 0.55 \\
\hline TAKAFUL-EM & 0.73 & 0.74 & 0.28 & 0.92 & 0.80 & 0.91 & 0.66 & 0.47 & 0.64 & 0.62 & 0.91 & 0.59 \\
\hline
\end{tabular}

TABLE II. CORRELATION AND COVARIANCE MATRIX AMONG THE 20 STOCKS 


\begin{tabular}{|c|c|c|c|c|c|c|c|c|c|c|c|c|c|}
\hline & & AL SALAM BANK & Dubai Islamic & Al Salam Bank- & Arabtec & Deyaar & & & & & GULFNA & & HitsTel \\
\hline & AJMAN BANK & SUDAN & Bank & Bahrain & Holding & Development & DSI & EMMAR & AIRARABIA & ARMX & $v$ & $D U$ & $e$ \\
\hline AJMAN BANK & 0.001554596 & & & & & & & & & & & & \\
\hline AL SALAM BANK SU & 0.002524966 & 0.006803878 & & & & & & & & & & & \\
\hline Dubai Islamic Bar & $-6.07493 E-05$ & 0.000680202 & 0.002960283 & & & & & & & & & & \\
\hline Al Salam Bank -Ba & 0.0049843 & 0.009605903 & 0.001468514 & 0.029208023 & & & & & & & & & \\
\hline Arabtec Holding & 0.006582224 & 0.015024118 & 0.006072452 & 0.031718714 & 0.050887164 & & & & & & & & \\
\hline Deyaar Developm! & 0.007024707 & 0.015332497 & 0.003291464 & 0.041608293 & 0.050715355 & 0.074880438 & & & & & & & \\
\hline DSI & 0.00105248 & 0.003887144 & 0.004151173 & 0.008123071 & 0.014191125 & 0.016663566 & 0.010945065 & & & & & & \\
\hline EMMAR & 0.00116808 & 0.002180784 & 0.003523952 & 0.006195964 & 0.012113075 & 0.011785716 & 0.008565451 & 0.009622948 & & & & & \\
\hline AIRARABIA & 0.000269898 & 0.001827548 & 0.003435212 & 0.006992491 & 0.010088873 & 0.014350357 & 0.006871277 & 0.004467412 & 0.0073415 & & & & \\
\hline ARMX & 0.001096519 & 0.002080482 & 0.000373404 & 0.00414263 & 0.006210682 & 0.005774001 & 0.000862017 & 0.001409936 & 0.000777327 & 0.001285127 & & & \\
\hline GULFNAV & 0.007170149 & 0.016006554 & 0.003381458 & 0.042076845 & 0.052007098 & 0.07146931 & 0.015328202 & 0.010756537 & 0.013274195 & 0.006165103 & 0.069867 & & \\
\hline DU & 0.000452188 & 0.001358911 & 0.000775312 & 0.002387212 & 0.003913503 & 0.005817912 & 0.003273682 & 0.002521186 & 0.001698486 & 0.000191802 & 0.005118 & 0.0012 & \\
\hline HitsTele & -0.003363286 & -0.000338816 & 0.012616477 & -0.00609206 & 0.01602287 & -0.007838681 & 0.014554592 & 0.010052866 & 0.009656669 & -0.001907303 & -0.00543 & 0.002 & 0.0823 \\
\hline UPP & 0.006725813 & 0.012974068 & 0.003269481 & 0.037151024 & 0.046917044 & 0.059794005 & 0.012772394 & 0.010283321 & 0.010621198 & 0.005491105 & 0.059185 & 0.0043 & -0.001 \\
\hline TAMWEEL & 0.00335632 & 0.005594361 & 0.002727563 & 0.022087537 & 0.026682585 & 0.041864663 & 0.011927268 & 0.009587553 & 0.008328674 & 0.001688668 & 0.038396 & 0.0043 & 0.0036 \\
\hline GFH & 0.003642091 & 0.010128457 & 0.004907605 & 0.021962325 & 0.033472803 & 0.036816685 & 0.011982793 & 0.008262196 & 0.008980745 & 0.003347778 & 0.036674 & 0.003 & 0.0167 \\
\hline AMAN & 0.013316635 & 0.023839549 & 0.002486913 & 0.06815772 & 0.084118856 & 0.108218536 & 0.014011376 & 0.013042102 & 0.015468919 & 0.012103218 & 0.108101 & 0.005 & -0.025 \\
\hline DARTAKAFUL & 0.003784652 & 0.007829117 & 7.10198E-05 & 0.017024384 & 0.020333101 & 0.0269693 & 0.004714537 & 0.003187856 & 0.003409888 & 0.002960674 & 0.026505 & 0.0017 & -0.0075 \\
\hline SALAMA & 0.005870093 & 0.012167559 & 0.003013522 & 0.032239969 & 0.04031181 & 0.053847577 & 0.01209609 & 0.009540921 & 0.010490706 & 0.0052456 & 0.052678 & 0.0039 & -0.0055 \\
\hline TAKAFUL-EM & 0.002841691 & 0.006069225 & 0.001528001 & 0.015546764 & 0.017875059 & 0.024608886 & 0.00681338 & 0.004604893 & 0.0054061 & 0.002191772 & 0.023931 & 0.0021 & -0.0017 \\
\hline
\end{tabular}

The minimum variance portfolio so obtained involved a standard deviation of $2.68 \%$ and the expected return of this portfolio was $3.31 \%$. This portfolio was composed of investments in three securities, namely, Dubai Islamic Bank $(6.15 \%)$, ARAMEX $(47.26 \%)$ and Emirate Integrated
Telecommunications Company (46.59\%).

\section{OPTIMAL PORTFOLIOS}

TABLE III. OPTIMAL PORTFOLIO WEIGHTS, STANDARD DEVIATION AND EXPECTED RETURN OF PORTFOLIO

\begin{tabular}{|c|c|c|c|c|c|c|}
\hline $\begin{array}{l}\text { Dubai } \\
\text { Islamic } \\
\text { Bank } \\
\text { (DIB) }\end{array}$ & $\begin{array}{c}\text { ARAMEX } \\
\text { (ARMX) }\end{array}$ & $\begin{array}{l}\text { Emirate Integrated } \\
\text { Telecommunications Company } \\
\text { (DU) }\end{array}$ & $\begin{array}{c}\text { Hits Telecom } \\
\text { Holding } \\
\text { HitsTele) }\end{array}$ & $\begin{array}{c}\text { Variance of } \\
\text { Portfolio }\end{array}$ & $\begin{array}{c}\text { Standard } \\
\text { Deviation of } \\
\text { Portfolio }\end{array}$ & $\begin{array}{l}\text { Expected return } \\
\text { of Portfolio }\end{array}$ \\
\hline $6.11 \%$ & $47.22 \%$ & $46.68 \%$ & $0.00 \%$ & 0.000719324 & $2.68 \%$ & $3.32 \%$ \\
\hline $6.00 \%$ & $47.24 \%$ & $46.75 \%$ & $0.00 \%$ & 0.000719332 & $2.68 \%$ & $3.33 \%$ \\
\hline $5.76 \%$ & $47.22 \%$ & $47.01 \%$ & $0.00 \%$ & 0.000719359 & $2.68 \%$ & $3.36 \%$ \\
\hline $5.85 \%$ & $47.03 \%$ & $47.11 \%$ & $0.01 \%$ & 0.000719376 & $2.68 \%$ & $3.37 \%$ \\
\hline $5.73 \%$ & $47.09 \%$ & $47.17 \%$ & $0.01 \%$ & 0.000719395 & $2.68 \%$ & $3.38 \%$ \\
\hline $4.99 \%$ & $47.30 \%$ & $47.57 \%$ & $0.14 \%$ & 0.000719743 & $2.68 \%$ & $3.55 \%$ \\
\hline $2.90 \%$ & $48.20 \%$ & $48.38 \%$ & $0.52 \%$ & 0.000721088 & $2.69 \%$ & $4.00 \%$ \\
\hline $1.97 \%$ & $48.60 \%$ & $48.74 \%$ & $0.69 \%$ & 0.000721868 & $2.69 \%$ & $4.20 \%$ \\
\hline $0.58 \%$ & $49.20 \%$ & $49.28 \%$ & $0.95 \%$ & 0.000723247 & $2.69 \%$ & $4.50 \%$ \\
\hline $0.00 \%$ & $48.17 \%$ & $50.41 \%$ & $1.42 \%$ & 0.000727579 & $2.70 \%$ & $5.00 \%$ \\
\hline $0.00 \%$ & $44.76 \%$ & $52.85 \%$ & $2.39 \%$ & 0.000753785 & $2.75 \%$ & $6.00 \%$ \\
\hline $0.00 \%$ & $41.36 \%$ & $55.28 \%$ & $3.36 \%$ & 0.00080382 & $2.84 \%$ & $7.00 \%$ \\
\hline $0.00 \%$ & $39.69 \%$ & $55.99 \%$ & $3.93 \%$ & 0.000871248 & $2.95 \%$ & $8.00 \%$ \\
\hline $0.00 \%$ & $38.10 \%$ & $56.62 \%$ & $4.48 \%$ & 0.000948411 & $3.08 \%$ & $9.00 \%$ \\
\hline $0.00 \%$ & $36.96 \%$ & $56.68 \%$ & $4.99 \%$ & 0.001035205 & $3.22 \%$ & $10.00 \%$ \\
\hline
\end{tabular}

Following the formation of the minimal variance portfolio, the standard deviation of the portfolio was continuously increased minimally, in order to obtain a collection of portfolios that have the maximum return for a specific level of risk. The optimal portfolios that were used to build the efficient frontier using UAE securities comprise of the weights as per shown in Table III. The expected return and the standard deviation of the optimal portfolios were plotted along the $\mathrm{Y}$ axis and the $\mathrm{X}$ axis respectively, to obtain the risk return plane, where the curve represents the efficient frontier. Portfolios that lie along the curve are optimal, because they provide maximum return at a specific level of risk or they have the least possible risk for a particular level of return [10]. Portfolios lying below the curve are not optimal in nature, as their returns can be maximized in spite of keeping their risk level constant. On the contrary, portfolios above the curve would be sought for but it is not possible to build such portfolios, as supported in [11]. It is generally acceptable in Modern Portfolio Theory that a line originating from the risk free rate on the $\mathrm{Y}$ axis and touching the risk return curve is the Capital Asset Allocation Line. Assuming the risk free rate to be $3 \%$ (based on the Emirates Interbank Lending rate), the line originating from it touches the efficient frontier at the point $(2.7 \%, 5 \%)$. This is the risk return value of the tangential portfolio or the optimal risky portfolio. This portfolio comprises of $48.17 \%$ investment in Aramex, 50.41\% investment in Emirate Integrated Telecommunications Company and $1.42 \%$ investment in Hits Telecom Holding. 


\section{CONCLUSIVE REMARKS}

It is a known fact that diversification of portfolio assists in the reduction of the associated risk involved in it. Nevertheless, it is worth mentioning that it is not possible to get rid of risk entirely by means of diversification. Even if the numbers of constituent securities in a particular portfolio are increased indefinitely, there would be certain level of risk associated with that portfolio. Nonetheless, the diversification benefits in terms of reduced associated risk rapidly decreases with the inclusion of more securities in the portfolio. This is evident standard deviation stabilizes out eventually. This suggests there is a definite risk level that is intrinsic in the investment of securities and this least level of risk cannot be eradicated even by increasing the number of securities in an investment portfolio indefinitely. This was clearly observed from the portfolio management analysis of the 20 stocks trading in the UAE markets. The study revealed that the use of 20 stocks could minimize the risk involved, however the risk or variance could not be made nil. Even the minimum variance portfolio developed from the 20 selected stocks had a standard deviation of $2.68 \%$. Future avenues of research could be taken to assess the implications of different risk profiles of different investors, and what combination of risky and risk free assets would be optimal for them.

\section{REFERENCES}

[1] R. A. Strong, Portfolio Construction, Management, and Protection, UK: Cengage Learning, 2008.

[2] F. K. Reilly and K. C. Brown, Investment Analysis and Portfolio Management, United States: Cengage Learning, 2011.

[3] Dubai Financial Markets. (December 2012). Listed Securities. [Online] Available: http://www.dfm.ae/pages/default.aspx?c=1010

[4] R. A. Ferri, All About Asset Allocation: The Easy Way to Get Started, USA: McGrawHill, 2005, pp. 25-135.

[5] C. P. Jones, Investments: Analysis and Management, USA: John Wiley and Sons, 2009, pp. 75-221.
[6] T. Poddig and A. Unger, "On the Robustness Of Risk-Based Asset Allocation," Financial Markets and Portfolio Management, vol. 26, no. 3, pp. 369-401, September 2012.

[7] W. Lee, "Risk-Based Asset Allocation: A New Answer to An Old Question?" Journal of Portfolio Management, vol. 37, no. 4, pp. 11-28, 2011

[8] W. Lee, "Risk On/Risk Off," Journal of Portfolio Management, vol. 38, no. 3, pp. 28-39, 2012.

[9] E. Girard and E. Ferreira, "A N-Assets Efficient Frontier Guideline for Investments Courses," Journal of College Teaching \& Learning, vol. 2, no. 1, 2005.

[10] W. F. Sharpe, "The Sharpe Ratio," Journal of Portfolio Management, vol. 21, no. 1, pp. 49-58, Fall 1994.

[11] W. F. Sharpe, "Adjusting For Risk In Portfolio Performance Measurement," Journal of Portfolio Management, vol. 1, no. 2, pp. 29-34, 1975.

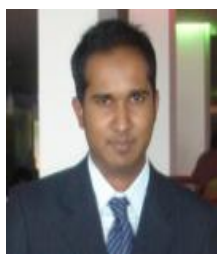

Gurrib I. is currently the MBA Finance Program Coordinator at the Canadian University of Dubai, which is ranked no. 1 in Dubai for its MBA program. $\mathrm{He}$ is a holder of a Ph.D. (Economics and Finance) from Curtin University, Australia, together with a MPA (Master of Professional Accounting) and MFin (Master of Finance) from Victoria State University, Australia. He held various academic positions in Australia, Saudi Arabia and UAE. He was also a finance manager at Westpac Bank, the 2nd largest bank in Australia.

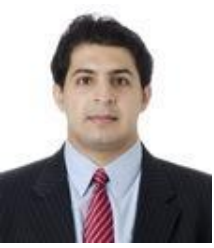

Alshahrani S. is currently an Economist, with the Fiscal Affairs Department of the International Monetary Fund (IMF) and is based in Washington, U.S. He previously held position at the Central Bank of Saudi Arabia (SAMA). He held some academic positions in USA \& GCC universities. He holds a Ph.D. (Economics) from Washington State University (USA) and 2 graduate degrees in applied economics and statistics. 